\title{
CRIAÇÃO DE DIRETRIZES PARA A AVALIAÇÃO DO DESEMPENHO AMBIENTAL DA INDÚSTRIA GRÁFICA
}

\author{
Leonardo Castillo, Ph.D \\ Universidade Federal de Pernambuco, UFPE \\ leonardo.castillo@ufpe.br \\ Lucídio Cardoso Leão \\ Universidade Federal de Pernambuco, UFPE \\ lucidio.leao@gmail.com
}

\begin{abstract}
Resumo: $O$ presente artigo tem como objetivo indicar diretrizes para realizar uma avaliação de desempenho ambiental da indústria gráfica, a partir da construção de uma ferramenta de coleta de dados. A primeira etapa discute os principais indicadores de qualidade ambiental no setor. Em seguida, apresenta alguns parâmetros da norma ISO 14031 e as diretrizes da Global Reporting Initiative - GRI, além de analisar três ferramentas ambientais de coleta de dados. Por fim, apresenta-se uma ferramenta, que contém 54 questões objetivas, específicas à indústria gráfica, contribuindo à determinação dos indicadores necessários à avaliação de desempenho ambiental do setor. Após a aplicação da ferramenta em várias empresas gráficas, foí possível identificar os principais aspectos e apresentar a realidade local com vistas ao desempenho ambiental.
\end{abstract}

Palavras-chave: avaliação ambiental, indústria gráfica, design para a sustentabilidade

Abstract: The objective of this paper is to define guidelines to assess the environmental performance of the graphic industry based on the development of a tool for data collecting. The first part of the research presents the main indicators of environmental quality used in printing industry. Then, environmental parameters of ISO 14031 and guidelines of Global Report Initiative are presented. The developed tool has 54 questions specific of the graphic industry. This tool contributes to determine the kind of indicators needed for the assessment of the environmental performance of the graphic sector. The tool was tested in several graphic industries, and during the testing phase it was possible to identify the main aspects and the local reality related to environmental performance.

Keywords: environmental assessment, graphic industry, design for sustainability 


\section{INTRODUÇÃO}

Um recente estudo da Associação Brasileira de Indústrias Gráficas, ABIGRAF mostrou como essa atividade cresceu em ritmo constante nos últimos 5 anos. Por exemplo, conforme esse relatório, a indústria gráfica brasileira transformou 6,5 milhões de toneladas de papel no ano de 2012 , o equivalente a mais de $70 \%$ de todo o papel disponível no mercado brasileiro, montante esse que representou um faturamento de quase $\mathrm{R} \$ 25$ bilhões. Soma-se a isso o fato do setor empregar mais de 270 mil pessoas em mais de 20 mil unidades produtivas. O parque gráfico brasileiro dispõe de 71 mil máquinas de impressão com uma média próxima a quatro impressoras por unidade produtiva. Conta ainda com 92 mil máquinas e equipamentos de acabamento e beneficiamento de produtos gráficos, totalizando mais de 163 mil máquinas instaladas na produção (ABIGRAF, 2012). Esses números nos levam inevitavelmente a pensar no impacto ambiental dos processos produtivos e nos desafios da indústria gráfica diante do paradigma da sustentabilidade.

Considerando-se que a maioria das empresas não conhece todos os impactos causados pela operação e desconhece também algumas inovações do setor, já em uso em outras regiões, o acesso a esse tipo de informação é uma necessidade premente e pode proporcionar um melhor desempenho ambiental e até redução de custo nessas empresas. Por outro lado, existem atualmente no mercado e na academia diversas normas, diretrizes e ferramentas que permitem entender melhor o processo de planejamento e seleção dos aspectos ambientais mais significativos, porém, seus conjuntos de indicadores não necessariamente são aplicáveis às práticas atuais da indústria gráfica brasileira, o que nos motivou a investigar esse setor e elaborar uma ferramenta específica para essa indústria.

Com essa motivação o presente estudo surgiu a partir da ideia de entender melhor como medir e avaliar esses números do ponto de vista do impacto gerado ao meio ambiente. Dessa forma, as questões norteadoras para essa investigação foram: quais são as atuais práticas e tendências ambientais nos processos gráficos?; e, quais são as atuais práticas e tendências de gestão ambiental na indústria gráfica?

Assim, este artigo tem como objetivo indicar diretrizes para realizar avaliação de desempenho ambiental da indústria gráfica, a partir da construção de uma ferramenta de coleta de dados. A ferramenta foi construída com base na análise dos principais indicadores de qualidade ambiental utilizados na indústria gráfica como as normas ambientais do ISO 14031 e as diretrizes da Global Reporting Initiative - GRI, além de analisar três ferramentas ambientais de coleta de dados. Ao longo do processo vários testes pilotos foram aplicados em empresas locais com o intuito de analisar sua viabilidade e adequação.

\section{ASPECTOS AMBIENTAIS DOS PROCESSOS GRÁFICOS E IMPRESSÃO EM OFFSET}

Após a primeira década do século XXI, o desenvolvimento da indústria gráfica passou por um momento de transição. De um lado, empresas investiram em novas tecnologias; de outro lado, a indústria gráfica tradicional, firmada numa tecnologia fadada à obsolescência, mantêm-se ainda hoje em atividade. Apesar das diferenças tecnológicas, os dois processos possuem o mesmo conceito, fundamentado em três principais etapas produtivas: pré-impressão, impressão e pós-impressão. 
Os processos de pré-impressão representam o inicio do processo gráfico e consistem na produção de alguns produtos, como clichê, fotolito e provas, e na realização de alguns serviços, como imposição eletrônica, computer-to-plate, etc, caracterizando-se como a preparação do material, para que possa ser impresso. A impressão é a etapa em que o projeto se transforma em página impressa. Os processos de impressão mais comuns na indústria gráfica brasileira são: tipografia, offset, rotogravura, flexografia, serigrafia e impressão digital. E por fim, a etapa de acabamento compreende todos os procedimentos realizados no material após a impressão. Esses procedimentos podem ser relevo, costura, cola, entre outros.

A partir disso torna-se relevante analisar e considerar os impactos ambientais dos processos anteriormente descritos, os quais apresentam impactos ao meio ambiente, e que podem ser classificados da seguinte forma, de acordo com a Abigraf Associação Brasileira da Indústria Gráfica (BARBOSA, 2009):

Consumo de matérias-primas: $O$ consumo de matérias-primas gera impactos ambientais devido à utilização de recursos naturais que representa; em seguida, por causa dos impactos indiretos associados às atividades de produção e transporte destas matérias-primas até a gráfica (Barbosa et al., 2009).

Consumo de água e energia: algumas operações do processo gráfico podem apresentar consumos significativos, como as operações de limpeza da impressão offset, visto que nesse processo, a imagem é transferida da chapa para uma banqueta e desta para o substrato. Este processo envolve consumo de água. Além desse consumo no processo industrial, existe ainda o consumo de água para outros fins, como o uso para fins sanitários. Um estudo aponta que o consumo de água para este fim pode chegar a ser 200 vezes maior que o consumo de água no processo industrial (MATUCHEVSKI, 2007).

Geração de resíduos sólidos: de acordo com a norma NBR 10004, a maioria dos resíduos sólidos gerados pela indústria gráfica são de classe IIA (inertes) ou IIB (não perigosos). A maior quantidade desses resíduos são aparas de papel, restos de filmes, de plásticos, de tinta e as embalagens dos insumos (tinta, cola, verniz, etc.) utilizados no processo. Há também a geração de resíduos Classe I-Perigosos, como restos de tinta, verniz ou solvente, encontrados em embalagens, panos e estopas sujos que são inflamáveis e, dependendo da cor, também podem conter metais pesados. As lâmpadas fluorescentes usadas também compõem essa lista.

Geração de efluentes líquidos: os efluentes do processo de revelação da chapa (fixador e revelador), efluentes fotográficos - para as gráficas que utilizam o processo analógico de gravação de chapa (CtF - Computer-to-film), processos de lavagem dos sistemas de entintamento da impressão, entre outros, são os principais impactos gerados nessa categoria. Algumas gráficas tem realizado alguns investimentos para reduzir a geração desses efluentes. No processo de composição da chapa, por exemplo, já existem equipamentos que gravam a chapa sem a necessidade de revelar. Isto evita a utilização de uma máquina específica para esse fim e torna desnecessário o uso de fixador e revelador, além de reduzir o consumo de água. Há também equipamentos acessórios que associados à impressora offset aumentam a vida útil dos filtros, reduzindo a quantidade de lavagens dos sistemas de entintamento. A função dos filtros é reter o excesso de tinta e químicos utilizados, reduzindo a contaminação da água. 
Emissões atmosféricas: no processo gráfico, as principais emissões atmosféricas são os Compostos Orgânicos Voláteis - VOC, que evaporam dos solventes, tintas e vernizes. Essas emissões podem ser recuperadas com o uso de equipamentos específicos, porem, devido aos altos custos, isso é bastante raro no setor gráfico brasileiro. Além disso, os VOCs gerados na atividade são de baixa quantidade, o que mais uma vez gera desmotivação para a instalação de equipamentos adequados, tornando o fato bastante raro no mercado brasileiro.

Ruído e vibrações: o uso de equipamentos como impressoras, alagadeiras, guilhotinas, entre outros geram ruídos e vibrações no ambiente de trabalho. Os maiores índices são identificados no uso de impressoras offset rotativa, quando o ruído chega a incomodar o colaborador interno. Para essas situações, as soluções de controle envolvem técnicas simples como alterações de disposição física dos equipamentos ou o uso de bases antivibratórias. Mas na maioria dos casos, o que as gráficas implantam é o uso de EPI's - Equipamentos de Proteção Individual, em especial os protetores auriculares, que proporcionam bom nível de redução de ruído.

Para elucidar tais impactos negativos apresenta-se no quadro 1 o fluxograma de entradas e saídas do processo de produção em offset. Na coluna de "entrada", estão listados os insumos e materiais necessários à realização, e na coluna saída estão "listados" os resíduos e efluentes como consequência à realização de cada etapa:

Quadro 1 - fluxograma de entradas e saídas do processo offset. Fonte Barbosa et al., 2009, p. 19.

\begin{tabular}{|c|c|c|}
\hline Entrada & Etapa & Saída \\
\hline $\begin{array}{l}\text { Filme } \\
\text { Revelador / fixador } \\
\text { Água }\end{array}$ & $\begin{array}{l}\text { Processamento da } \\
\text { imagem (sistema } \\
\text { convencional) }\end{array}$ & $\begin{array}{l}\text { Filmes usados } \\
\text { Efluentes fotográficos saturados }\end{array}$ \\
\hline $\begin{array}{l}\text { Chapa de alumínio } \\
\text { Revelador e fixador } \\
\text { Goma } \\
\text { Água }\end{array}$ & Confecção da fôrma & $\begin{array}{l}\text { Retalhos de chapa de alumínio } \\
\text { Efluentes fotográficos }\end{array}$ \\
\hline $\begin{array}{l}\text { Tinta pastosa e verniz } \\
\text { Substrato de impressão } \\
\text { Chapa de aluminio } \\
\text { Soluçăo de fonte } \\
\text { Blanquetas } \\
\text { Panos, toalhas ou estopas de limpeza } \\
\text { Pó anti-maculante } \\
\text { Solvente para limpeza }\end{array}$ & Impressão & $\begin{array}{l}\text { Latas de tinta e verniz vazias } \\
\text { Aparas de substrato com ou sem impressão } \\
\text { Chapa de alumínio usada } \\
\text { Efluentes liquidos } \\
\text { Blanquetas usadas } \\
\text { Panos/toalhas de limpeza com solventes } \\
\text { VOCs - Compostos Orgânicos Voláteis } \\
\text { Residuos de pó } \\
\text { Solvente sujo }\end{array}$ \\
\hline $\begin{array}{l}\text { Cola } \\
\text { Plásticos de embalagem } \\
\text { Papel e papelăo de embalagem } \\
\text { Pallets e tampas de madeira } \\
\text { Tubetes } \\
\text { Lâminas de corte }\end{array}$ & Pós-impressāo & $\begin{array}{l}\text { Residuos de cola } \\
\text { Resíduos plásticos } \\
\text { Poeira de papel } \\
\text { Residuos de madeira } \\
\text { Aparas de substrato } \\
\text { Lâminas usadas }\end{array}$ \\
\hline $\begin{array}{l}\text { Fita adesiva } \\
\text { Embalagens de papel e plástico } \\
\text { Papelăo ondulado } \\
\text { Presilhas metálicas } \\
\text { Pallets e tampas de madeira }\end{array}$ & Produto final & $\begin{array}{l}\text { Resíduos de fita adesiva } \\
\text { Resíduos de papel e plástico } \\
\text { Resíduos de papelāo } \\
\text { Restos de presilhas metálicas }\end{array}$ \\
\hline
\end{tabular}

\subsection{Produção Mais Limpa}

Entende-se a Produção Mais Limpa $(\mathrm{P}+\mathrm{L})$ como uma aplicação continuada de uma estratégia econômica, ambiental e tecnológica integrada aos processos produtivos que permite aumentar a eficiência no uso de matérias-primas, água e energia de forma preventiva e que proporciona redução dos riscos para a saúde e o meio ambiente. Considerar a $\mathrm{P}+\mathrm{L}$ como caminho para os impactos ambientais passa por entender o desenho hierárquico de suas estratégias de funcionamento (Figura 1) 
considerando-se principalmente que se os poluentes que não podem ser reduzidos na fonte (nível 1), devem, preferencialmente, ser reintegrados ao processo de produção da empresa (nível 2); na sua impossibilidade, tornam-se adequadas as medidas de reciclagem fora da empresa (nível 3).

Como vantagens da implantação da $\mathrm{P}+\mathrm{L}$ tem-se: redução de custos pela otimização do uso de matérias-primas, energia, água e outros recursos; redução de riscos e responsabilidades derivadas; melhores condições de segurança e saúde ocupacional, entre outros.

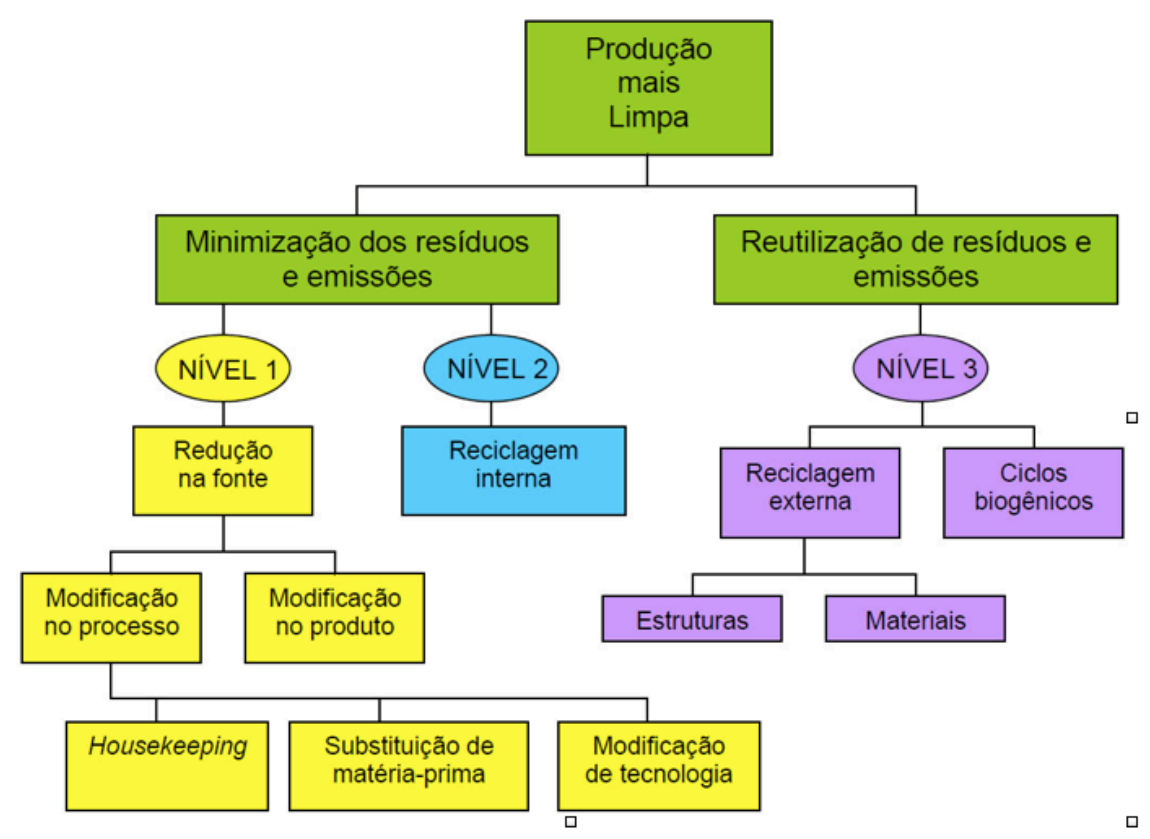

Figura 1 - Desenho das estratégias de funcionamento da P+L .Fonte: Centro Nacional de Tecnologias Limpas - SENAI, 2010.

Em anuência a esse raciocínio, Barbosa e colaboradores (2009, p.37) estabelecem que a implantação dessa ferramenta deve seguir a seguinte prioridade, para obter mais vantagens ambientais: 1) eliminação ou redução do uso de matériasprimas ou materiais tóxicos; 2) melhoria nos procedimentos operacionais e na aquisição e estoque de materiais; 3) uso eficiente dos insumos (água, energia, matérias-primas, etc.); 4) eliminação ou redução da geração de quaisquer rejeitos (sólidos, líquidos, gás, etc.); 5) reuso ou reciclagem dentro do processo; 6) reuso ou reciclagem fora do processo; 7) tratamento de efluentes e resíduos; 8) recuperação de área contaminada.

\section{FERRAMENTAS PARA AVALIAÇÃO DO IMPACTO AMBIENTAL}

A série de normas ISO 14000 estabelece diretrizes para um processo de Avaliação do Desempenho Ambiental (ADA) baseada em um processo contínuo de coleta e avaliação de dados que se utiliza de auditoria ambiental para verificar a conformidade de acordo com requisitos definidos classificados em Indicadores de Desempenho Ambiental (IDA) e Indicadores de Condições Ambientais (ICA). O primeiro é composto de Indicadores de Desempenho Gerencial e de Desempenho Operacional, enquanto o segundo em indicadores que tratam das condições da água, do ar, solo, flora, fauna, humano, estética, etc. 
Já o GRI disponibiliza as diretrizes para elaboração de relatórios de sustentabilidade através de um modelo que é reconhecido como o mais completo e difundido, utilizando-se de indicadores de desempenho (essenciais e adicionais) que expõem informações sobre o desempenho ambiental, econômico e social da organização e, passíveis de comparação. Ao observar apenas os indicadores ambientais é possível verificar que as questões abrangem insumos (como material, energia, água) e produção (emissões, efluentes, resíduos). Além disso, abarcam o desempenho relativo à biodiversidade, à conformidade ambiental e outras informações, tais como gastos com meio ambiente e os impactos de produtos e serviços (GRI, 2006, p. 27).

Voltada à estratégia de design gráfico, o Scorecard da sustentabilidade é uma ferramenta desenvolvida pela Celery Design Collaborative que ajuda a decidir quais materiais os designers devem utilizar e quais devem evitar, na elaboração de um projeto, com vistas ao impacto ambiental. Isso se dá através de um sistema "Verde, Amarelo e Vermelho" para avaliar os materiais rapidamente a partir de três fatores: fonte, energia e destino.

\section{DIRETRIZES PARA A AVALIAÇÃO DE DESEMPENHO AMBIENTAL DA INDÚSTRIA GRÁFICA}

Ao observar o setor industrial gráfico com vistas à questão ambiental, esta pesquisa evidenciou a complexidade do tema. Após compreender o problema e percorrer iniciativas esta sessão apresenta o processo de elaboração de diretrizes para a avaliação do desempenho ambiental da indústria gráfica.

A base para a construção de tais diretrizes aqui proposta está alicerçada nos princípios de Produção Mais Limpa $(\mathrm{P}+\mathrm{L})$, e a ferramenta está dividida em 4 grandes grupos de questões: perfil da empresa, políticas de gestão ambiental, equipamentos e tecnologia utilizados e gestão de resíduos e efluentes do processo.

O perfil da empresa fornece informações sobre o contexto geral de organização da empresa, incluindo colaboradores e condução dos processos gráficos. A parte de gestão correlaciona a empresa com situações externas, explicando a posição da gráfica em relação ao contexto que a circunda. As questões sobre equipamentos e tecnologias expõem informações técnicas que influenciam no desempenho ambiental. Por fim, a parte de resíduos e efluentes oferece os dados referentes ao fluxograma do sistema, apresentando as saídas de varias etapas do processo.

Para a construção da ferramenta de diagnóstico do desempenho ambiental da indústria gráfica foram selecionados os seguintes conjuntos de diretrizes, normas e iniciativas:

- da norma ISO14031: os indicadores de desempenho ambiental;

- das diretrizes para publicação do Global Report Initiative: os indicadores chamados de essenciais das categorias: materiais (2 deles); energia (2); água (1); biodiversidade (2); emissões, efluentes e resíduos (6); produtos e serviços (2); e conformidade (1));

- da ferramenta de Análise de Gestão Ambiental: número de funcionários; e, publicação de informações sobre suas práticas ambientais. 
- Dos indicadores definidos por Matuchevski (2007): características individuais sobre cada material - insumos e matérias-primas utilizados pela gráfica, com o consumo médio mensal.

- Do Scorecard de Sustentabilidade: indicadores sobre o nível de informação da indústria gráfica em relação às novidades tecnológicas e a disponibilidade para utilização no mercado local. Além disso foi considerada a ponderação do impacto ambiental dentro de todo o sistema de produção apresentada pela ferramenta.

O diagnostico preliminar da ferramenta foi realizado com alunos da disciplina "sustentabilidade na produção gráfica" oferecida no curso de graduação em design, durante o semestre 2009.2. Seguidamente, realizados 2 testes piloto em industrias gráficas locais. Finalmente foram realizados alguns ajustes de acordo com o resultado de 2 entrevistas; uma com a Bracelpa - Associação Brasileira de Celulose e Papel, e outra com a Abigraf - Associação Brasileira da Indústria Gráfica e, posteriormente a ferramenta foi aplicada em sete indústrias gráficas de pequeno.

\subsection{A aplicação da ferramenta na indústria gráfica}

As 456 empresas gráficas em atividade no estado converteram, em 2008, 196.471 toneladas de papel, o que representa $57 \%$ do mercado da região, empregando 6.207 funcionários e faturarando 468 milhões de reais em 2008 (ABIGRAF, 2009b, p. 52). No entanto, não mais de quarenta são consideradas médias ou grandes empresas e, a maioria dessas empresas possui menos de 10 funcionários.

No estudo, menos de metade das gráficas possui licenciamento ambiental e apenas aquelas quarenta destacadas anteriormente são capazes de pagar por algum serviço ambiental. Ou seja: "falar de consciência ambiental só tem repercussão da média gráfica para cima" (informação verbal). A partir disso, selecionou-se sete indústrias gráficas de pequeno porte para compor os casos aqui estudados, cujo perfil é apresentado no Quadro 3.

Quadro 3 - Perfil das empresas entrevistadas. Fonte: Elaboração própria.

\begin{tabular}{|c|c|c|c|c|c|c|c|}
\hline \multicolumn{8}{|c|}{ GRAFICAS / PERFIL } \\
\hline INDICADORES & GRAFICA E & GRAFICA F & GRAFICA G & GRAFICA H & GRAFICA I & GRAFICA J & GRAFICA K \\
\hline N' DE FUNCIONÁRIOS & $001-010$ & $001-010$ & 001-010 & $001-010$ & 001-010 & $001-010$ & $001-010$ \\
\hline CONFECÇĀO DA CHAPA & $\begin{array}{l}\text { CIP e fotolito } \\
\text { terceirizados }\end{array}$ & $\begin{array}{l}\text { Fotolito na } \\
\text { própria gráfica }\end{array}$ & $\begin{array}{l}\text { Fotolito na } \\
\text { própria grafica }\end{array}$ & $\begin{array}{l}\text { Fotolito na } \\
\text { própria gráfica }\end{array}$ & $\begin{array}{l}\text { CIP e fotolito } \\
\text { terceirizados }\end{array}$ & CtP terceirizado & CtP terceirizado \\
\hline PROCESSOS TERCEIRIZADOS & 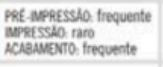 & 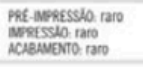 & 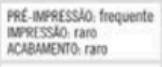 & 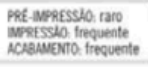 & 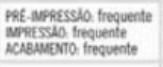 & 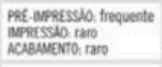 & 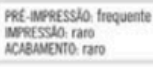 \\
\hline PAPEL MAIS CONSUMIDO & Offset e Couché & Offset e Couché & Couché & Offset & Offset e Couché & Offset & Offset \\
\hline
\end{tabular}

Em relação à "Gestão Ambiental", tem-se o seguinte cenário (Quadro 4): Com exceção da segunda linha (acerca de intimação em fiscalização ambiental), todas as outras questões foram respondidas como negativas pelos entrevistados. Das sete gráficas, apenas duas possuem licenciamento ambiental concedido pelo órgão ambiental do estado. Cinco já passaram por algum treinamento, e apenas duas gráficas nunca realizaram ações de auditoria. Há um indicativo que essa lacuna tenha sido 
preenchida pelas ações da Abigraf que ofereceu treinamento sobre destinação de resíduos e licenciamento ambiental.

Quando o assunto adentra a questão da certificação, nenhuma das gráficas pesquisadas possui ou já possuiu certificação ambiental. Como decorrência, também não publicam qualquer informação sobre as práticas ambientais. Finalmente, uma questão sobre o uso de fardamento por parte dos funcionários. A essa indagação, três gráficas responderam que não fazem uso; duas gráficas, que todos os funcionários usam; e as duas seguintes disseram não se aplicar essa situação.

Quadro 4: Indicadores de gestão ambiental das gráficas entrevistadas. Fonte: Elaboração própria.

\begin{tabular}{|c|c|c|c|c|c|c|c|}
\hline \multicolumn{8}{|c|}{ GRÁFICAS / GESTÃO } \\
\hline INDICADORES & GRAFICA E & GRAFICA F & GRAFICA G & GRAFICA H & GRAFICA I & GRAFICA J & GRAFICA K \\
\hline $\begin{array}{l}\text { POSSUI LCENCIAMERTO } \\
\text { AMBIERTAL? QUEM CONCEDEU? }\end{array}$ & $x$ & $\mathrm{x}$ & $\times$ & $\mathrm{x}$ & $\times$ & O & O \\
\hline $\begin{array}{l}\text { IA Fou IRTimado EM } \\
\text { Fiscatzacho AMBiental? }\end{array}$ & 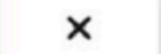 & 0 & $\mathrm{X}$ & $\mathrm{x}$ & $\mathrm{x}$ & $x$ & $x$ \\
\hline $\begin{array}{l}\text { IA REALZOU AUDTITRLA OU } \\
\text { TREINAMENTO AMBIERTAL? }\end{array}$ & O & O & $x$ & O & $\times$ & Orescues infustrias & 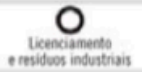 \\
\hline 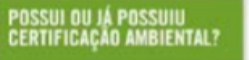 & $\times$ & $\mathrm{x}$ & $\mathrm{x}$ & $\mathrm{x}$ & $x$ & $\mathrm{x}$ & $\mathrm{x}$ \\
\hline $\begin{array}{l}\text { PUBULCA INFORMACOES SOBRE } \\
\text { AS PRAATICAS AMBIERTALIS? }\end{array}$ & $x$ & $x$ & $x$ & $x$ & $x$ & $x$ & $x$ \\
\hline $\begin{array}{l}\text { COMO SE OA O USO DE FARDAS } \\
\text { PEIOS FUNClONARTOS? }\end{array}$ & $\begin{array}{l}\text { Nāo faz uso } \\
\text { de fardamento }\end{array}$ & Todos utilizam & Outra situaçāo & Todos utilizam & Outra situaçāo & $\begin{array}{l}\text { Nāo faz uso } \\
\text { de fardamento }\end{array}$ & $\begin{array}{l}\text { Não faz uso } \\
\text { de fardamento }\end{array}$ \\
\hline
\end{tabular}

Ao se questionar sobre "Equipamentos e Tecnologias" (Quadro 5), tem-se que das sete gráficas, quatro oferecem impressão digital aos clientes. Essa situação provavelmente é influenciada pelo porte da empresa. A oferta de impressão digital é uma das alternativas para esse competitivo mercado. Três empresas não responderam sobre a quantidade de impressoras que possui. Isso pode está associado ao sigilo da informação ou mesmo porque não possuem esse tipo de equipamento. Essa última alternativa é pouco provável, visto que imprimir é a atividade motora da indústria gráfica.

Quadro 5 - Indicadores sobre equipamentos e tecnologias. Fonte: Elaboração própria. 


\begin{tabular}{|c|c|c|c|c|c|c|c|}
\hline \multicolumn{8}{|c|}{ GRÁFICAS / EQUIPAMENTOS E TECNOLOGIAS } \\
\hline INDICADORES & GRAFICA E & GRAFICA F & GRAFICA G & GRAFICA H & GRAFICA I & GRAFICA J & GRAFICA K \\
\hline $\begin{array}{l}\text { OFERECE IMPRESSIO } \\
\text { DIGTIAL AOS CLIERIES? }\end{array}$ & $\mathrm{O}$ & $\mathrm{O}$ & O & $\times$ & O & $\mathrm{x}$ & $\mathrm{x}$ \\
\hline $\begin{array}{l}\text { QUANTAS IMPRESSORAS } \\
\text { OFFSEI POSSUI? }\end{array}$ & Não respondeu & Não respondeu & 02 (duas) & Năo respondeu & 01 (uma) & 02 (duas) & 02 (duas) \\
\hline $\begin{array}{l}\text { QUAATOS CASTELOS } \\
\text { DE IMPRESSAO AO TOTAL? }\end{array}$ & Até 4 & Não respondeu & Até 4 & Até 4 & Até 4 & Até 4 & Até 4 \\
\hline $\begin{array}{l}\text { CONHECE IMPRESSIOA } \\
\text { OFFSET SECO? }\end{array}$ & $x$ & 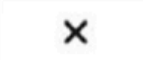 & $\mathrm{X}$ & 0 & $\mathrm{O}$ & $x$ & $x$ \\
\hline $\begin{array}{l}\text { CONHECE TEENOLOGIA } \\
\text { OUE DISPESASA EAPA } \\
\text { DE REVELCAOA OA CHAPA? }\end{array}$ & $\underset{\text { mas ndo utiliza }}{\mathrm{O}}$ & $\mathbf{x}$ & $\underset{\text { mas n̊outiliza }}{\mathrm{O}}$ & $\mathbf{x}$ & mas ndo uttiliza & $\underset{\text { mas nâo utiliza }}{\mathrm{O}}$ & $\underset{\text { mas n̊̊o utiliza }}{\mathrm{O}}$ \\
\hline 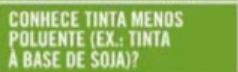 & $\mathrm{x}$ & $x$ & $\times$ & $\mathrm{x}$ & $\mathrm{x}$ & uthiza & Otiza \\
\hline 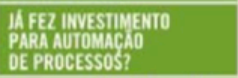 & $\mathrm{X}$ & $\mathrm{x}$ & $\mathrm{X}$ & $\mathrm{X}$ & $\mathrm{X}$ & $x$ & $x$ \\
\hline $\begin{array}{l}\text { CONHECEE EOUPAMEYTO QUE } \\
\text { REDUZ CONSUMO DE AGUA } \\
\text { EFILTOS KA IMPRESSORA? }\end{array}$ & $x$ & $x$ & $x$ & $x$ & $x$ & $x$ & $x$ \\
\hline $\begin{array}{l}\text { ENTRE OS EQUIPAMENTOS } \\
\text { OAGRAFICA. OUAL CONSOME } \\
\text { MAIS ENERGIA? }\end{array}$ & $\begin{array}{l}\text { Impressora } \\
\text { offset }\end{array}$ & Nāo respondeu & $\begin{array}{l}\text { Máquina } \\
\text { de corte }\end{array}$ & Não respondeu & $\begin{array}{l}\text { Impressora } \\
\text { offset }\end{array}$ & $\begin{array}{l}\text { Impressora } \\
\text { digital }\end{array}$ & $\begin{array}{l}\text { Impressora } \\
\text { offset }\end{array}$ \\
\hline
\end{tabular}

Uma empresa que não imprime dificilmente seria considerada uma gráfica. Apesar disso, vale o destaque, já que as sete empresas terceirizam processos de impressão - cinco raramente e duas frequentemente. Ainda nessa questão de impressoras offset, é raro que as gráficas com até dez funcionários possuam máquinas robustas. A grande maioria possui maquina monocolor ou bicolor.

Dois informantes conhecem impressão offset seco e cinco conhecem tecnologia que dispensa a etapa de revelação da chapa. Entre essas cinco empresas, uma diz que não usa essa tecnologia porque não está disponível no mercado, enquanto as outras quatro afirmam que terceirizam a gravação da chapa e o fornecedor não possui esse tipo de equipamento.

Uma surpresa positiva desse bloco temático (equipamentos e tecnologias) ficou por conta da questão sobre tinta menos poluente. Das sete gráficas pesquisadas, duas não só afirmaram conhecer esse tipo de produto, como asseguraram que utilizam tinta à base vegetal. Em relação ao conhecimento de novos equipamentos e investimento nessas tecnologias, as gráficas demonstraram certa deficiência, pois nenhuma delas fez investimento em automação de processos. Entre os equipamentos que consomem mais energia, três empresas afirmaram ser a impressora offset; uma afirmou ser a impressora digital e uma a maquina de corte. Duas gráficas não responderam a essa questão.

Quadro 6 - Indicadores sobre resíduos e efluentes. Fonte: Elaboração própria. 


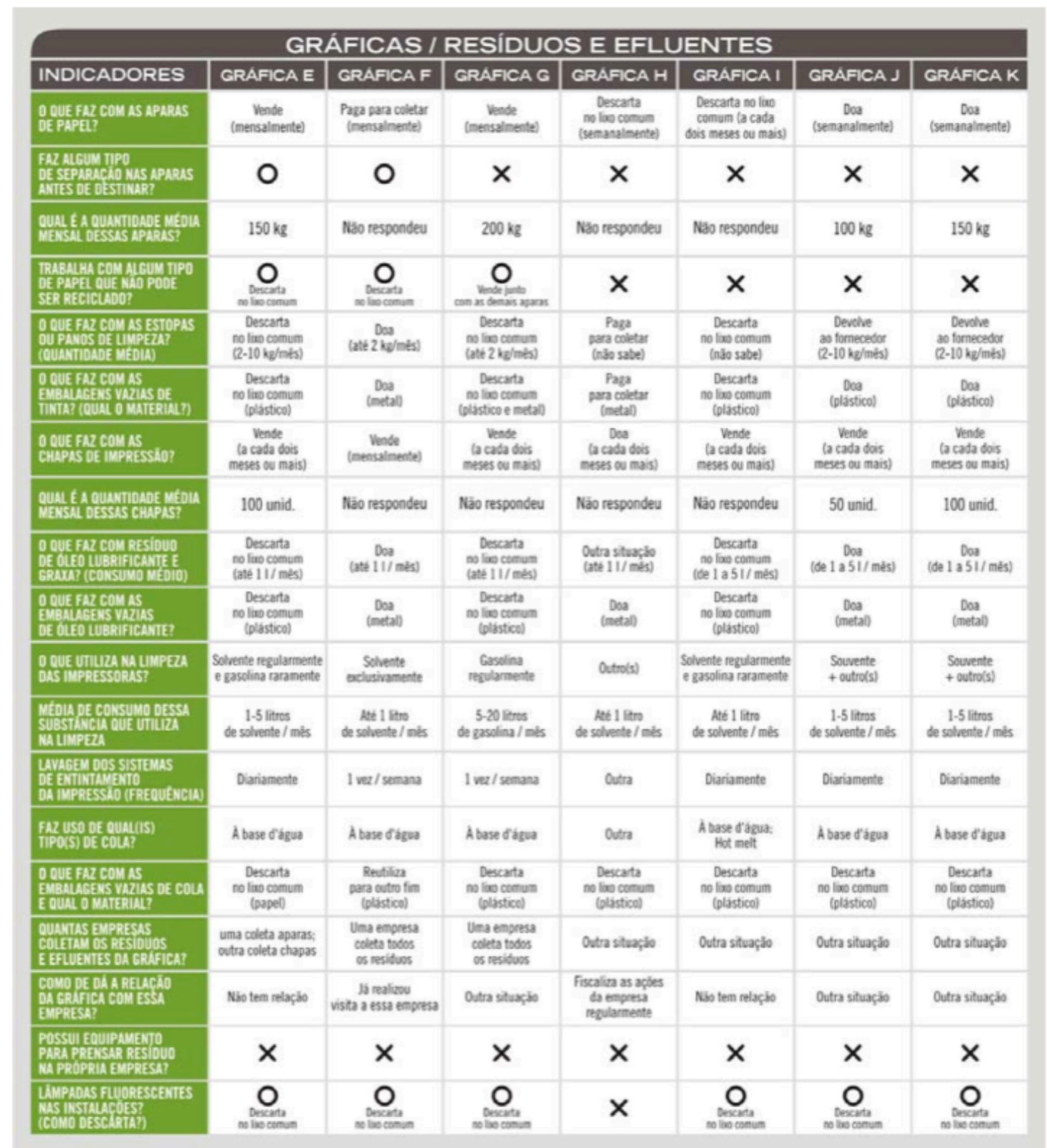

O bloco temático "Resíduos e Efluentes" (quadro 6) compõe o tema mais preocupante do setor. Em relação as aparas de papel, das sete empresas pesquisadas: duas descartam no lixo comum, duas doam e apenas duas gráficas vendem as aparas de papel, enquanto que uma das gráficas chega a pagar pela coleta desse tipo de resíduo. Essa diversidade de ações com esse tipo de resíduo é, certamente, influenciada pelo porte da empresa. Isto é: como são pequenas gráficas (não ultrapassam 200 quilos mensais) o consumo não justifica a adesão de uma empresa que coleta essas aparas.

Seis empresas conseguem vender as chapas de impressão, mas para isso, precisam armazená-las durante mais de dois meses, o que não chega a ser um problema, já que esse material ocupa um volume pequeno e necessita de pouco espaço para ser armazenado - diferentemente das aparas de papel. Ainda assim, a quantidade dessas chapas é reduzida, não ultrapassando 100 unidades, para uma estimativa mensal otimista. 
Entre as gráficas que responderam ao questionário, e outras que possuem perfil similar, é comum a utilização de papel do tipo autocopiativo ou carbono, por causa da demanda por impressão de notas ficais e formulários contínuos. Três das sete gráficas utilizam esse tipo de papel, que não pode ser reciclado, devido as suas características. Nessas três empresas, as aparas não possuem o tratamento adequado: são descartadas em lixo comum ou vendidas junto com as demais aparas.

Quando questionados sobre como é feito o tratamento de resíduos que são classificados pela NBR 10004 como Classe I - Perigosos as respostas foram: em relação as estopas, três gráficas descartam no lixo normalmente, duas utilizam estopas retornáveis (o fornecedor recolhe periodicamente, à medida que deixa outras limpas), uma gráfica paga para coletar e, outra doa. Situação parecida ocorre com as embalagens de tinta, óleo lubrificante, cola e solvente. Com exceção que, nestas últimas, os respectivos fornecedores não coletam, então as gráficas descartam em lixo comum, doam ou, pagam pelo recolhimento.

Sobre a substância utilizada na limpeza das impressoras, três gráficas afirmaram utilizar gasolina. Apenas uma gráfica afirmou utilizar exclusivamente o solvente adequado à função. E em relação ao descarte de lâmpadas fluorescentes seis disseram que as descartam no lixo comum. Para finalizar, as empresas que coletam os resíduos nessas gráficas, uma das entrevistadas respondeu que tem relação com duas empresas: uma para coletar aparas e outra para coletar as chapas. Os demais resíduos são de responsabilidade da própria gráfica, sendo a maior parte descartada em lixo comum. $O$ destaque à essa questão está no fato de que quatro empresas afirmaram não se enquadrar em nenhuma das situações oferecidas na ferramenta. Seria preciso uma averiguação mais cuidadosa para identificar quais são as práticas dessas empresas. O Quadro 5 apresenta o resultado da pesquisa em relação ao manejo de resíduos e efluentes

\subsection{Discussão sobre a ferramenta}

Primeiramente, fica o registro que a ferramenta construída atingiu os objetivos propostos. Indica alguns dos principais indicadores de qualidade ambiental na indústria gráfica, contribuindo com a avaliação de desempenho ambiental das empresas do setor (especialmente a indústria gráfica estudada). Com sua aplicação, a ferramenta ratifica a destinação dos resíduos e efluentes como principal problema do setor.

Importante também registrar algumas limitações da ferramenta, enquanto instrumento de coleta de dados. Restrições essas constatadas apenas durante o processo de aplicação nas sete gráficas e durante reunião da Abigraf, não sendo percebidas durante a aplicação dos pilotos ou no estudo de caso. Por exemplo: é preciso demarcar melhor os "blocos temáticos" da ferramenta, para que sejam mais bem caracterizados (perfil; gestão; equipamentos e tecnologias; resíduos e efluentes).

\section{CONCLUSÃO}

Como resultado esta pesquisa apresenta uma ferramenta com a finalidade de: (i) promover a compreensão do cenário do setor gráfico com vistas à preocupação ambiental; (ii) fomentar a conscientização dos empresários da indústria gráfica local; e (iii) subsidiar a elaboração de novas pesquisas no setor. Estas realizações são 
necessárias, visto o grande crescimento que a indústria gráfica pernambucana apresenta.

E isso vai de encontro à solução de uma das maiores lacunas encontradas em base de dados sobre o setor gráfico que é a disponibilização de informações particulares sobre a atuação ambiental das empresas que o compõem. Muitos dos dados disponíveis até então são aplicáveis a qualquer setor empresarial e, em geral, possuem foco econômico. A aplicação da ferramenta possibilitou a coleta de informações essenciais, pois a publicação de informações ambientais não é uma prática comum entre as empresas do setor.

$\mathrm{Na}$ medida em que as operações das empresas gráficas estão associadas a possíveis impactos ambientais, a principal dificuldade do setor está na destinação final dos resíduos e efluentes industriais. De tal forma, esta pesquisa identifica esses principais aspectos e apresenta a realidade local, a partir de informações coletadas de forma sistêmica e de fontes apropriadas. Constatou-se também que os empresários do setor não dão a atenção necessária ao descarte de resíduos e efluentes, sendo o descarte desses resíduos em lixo comum uma prática do setor, principalmente nas gráficas de pequeno e médio porte. Além disso, quando contratam empresas para realizar essa coleta, as gráficas não fiscalizam adequadamente o procedimento posterior ao da coleta, realizando o simples encaminhamento dos resíduos e efluentes.

Por outro lado, as gráficas que já foram vistoriadas afirmam que a CPRH Agência Estadual de Meio Ambiente não sabe indicar a solução para certos problemas. A Agência exige que a gráfica de a destinação correta aos resíduos perigosos - Classe I, mas não indica como realizar esse tipo de coleta. A maioria das gráficas reclama, por exemplo, de que não há empresas capacitadas para coletar estes resíduos na Região.

A maioria das gráficas não possui e nunca possuiu certificação ambiental. A aplicação da ferramenta evidenciou essa realidade nas pequenas gráficas, mas essa é uma realidade geral do setor. Entre as gráficas visitadas durante a pesquisa, apenas três possuem licenciamento ambiental. Essa relação também pode ser estabelecida com a certificação ambiental.

Além dessas questões legislativas, há ainda, e não menos importante, a questão mercadológica. Ao compreender o que deve ser feito para melhorar o desempenho ambiental, as empresas percebem suas vantagens e desvantagens competitivas em relação as demais - o que pode indicar o caminho dos futuros investimentos. A aplicação da ferramenta pode contribuir também com a identificação desse panorama.

Como desdobramentos da pesquisa pretende-se publicar informações coletadas para viabilizar possíveis análises comparativas que venham a ser realizadas futuramente.

\section{REFERÊNCIAS}

ABIGRAF, 2012. 16o Anuário Brasileiro da Indústria Gráfica. São Paulo: Clemente e Gramani,

ABIGRAF, 2012b. Estudo Setorial da Indústria Gráfica no Brasil. São Paulo: Abigraf. 
BARBOSA, Daniele de O. [et al.] 2009. Guia Técnico Ambiental da Indústria Gráfica [2a. Ed.]. São Paulo: CETESB: SINDIGRAF

BELLEN, Hans Michael Van, 2008. Indicadores de sustentabilidade: uma análise comparativa. [2a edição, 2a reimpressão]. Rio de janeiro: Editora FGV.

CENTRO NACIONAL DE TECNOLOGIAS LIMPAS, SENAI 2013. O que é Produção mais Limpa?<http://wwwapp.sistemafiergs.org.br/portal/page/portal/sfiergs_senai_uos/se nairs_uo697/O\%20que\%20\%E9\%20Produ\%E7\%E3o\%20mais\%20Limpa.pdf>. Acessado em 22 de junho de 2013.

DOUGHERTY, Brian, 2008. Green Graphic Design. New York: Allworth Press.

GRI - Global Reporting Initiative, 2007. Diretrizes para relatório de sustentabilidade, versão 3.0 [Ed. bras.: Gláucia Térreo (Coordenacão). São Paulo.

ISO14031. Gestão ambiental: avaliação do desempenho ambiental - Diretrizes. International Organization for Standardization (ISO).

MATUCHEVSKI, Karine: Desempenho ambiental: estudo de caso em uma indústria gráfica. 2007. Dissertação de mestrado. Universidade Federal de Santa Maria. 